\title{
Chronic active Epstein-Barr virus infection manifesting as coronary artery aneurysm and uveitis
}

\author{
Haijuan Xiao ${ }^{1 \dagger}$, Bing Hu${ }^{1 \dagger}$, Rongmu Luo ${ }^{2}$, Huili Hu ${ }^{1}$, Junmei Zhang ${ }^{3}$, Weiying Kuang ${ }^{3}$, Rui Zhang ${ }^{4}$, Li Li ${ }^{5}$
} and Gang Liu" ${ }^{1 *}$

\begin{abstract}
Background: Chronic active Epstein-Barr virus (CAEBV) infection is a type of lymphoproliferative disorder characterized by chronic or recurrent infectious mononucleosis (IM)-like symptoms, which can have less-frequent clinical presentations. The prognosis of CAEBV is poor, and hematopoietic stem cell transplantation (HSCT) has been shown to be the only potentially effective treatment. In this article, we present a special CAEBV case of a patient who had no typical IM-like symptoms at the early stage, but manifested with severe and progressive coronary artery aneurysm (CAA), abdominal aortic lesions, and severe uveitis. These manifestations were uncommon features and could only be blocked by HSCT.
\end{abstract}

Case presentation: A 4-year-old girl with no special medical history complained of decreased vision for 10 months and cough after physical activities for three months. The blurred vision grew rapidly worse within one month, until only light perception remained. She was diagnosed with uveitis and cataract, and received prednisone and ciclosporin A treatment. However, her vision did not improve. Physical examination showed slight hepatosplenomegaly. Ultrasonic cardiogram showed bilateral CAA (5.0 mm and $5.7 \mathrm{~mm}$ for inner diameters), and abdominal CT scan revealed a thickened aortic wall, as well as stenosis and dilation of the segmental abdominal aorta. Other significant findings were increased EBV-DNA $\left(3.29 \times 10^{4}\right.$ copies $\left./ \mathrm{mL}\right)$ from peripheral blood, positive EBV antibodies (EBV-CA-lgG, EBV-EA-IgA, and EBV-NA-lgG), and positive EBV-encoded small RNAs found by bone marrow biopsy. Based on her clinical manifestations and evidence for EBV infection, we diagnosed CAEBV. She received allogeneic HSCT, and the cataract operation was performed after HSCT. EBV-DNA could not be detected in peripheral blood after HSCT. Her CAAs did not progress, and uveitis was well controlled. Her vision recovered gradually over the 3 years after HSCT.

Conclusions: We present a rare CAEBV case of a patient who suffered from uncommon and severe cardiovascular and ocular involvement that was relieved by HSCT. Therefore, early recognition and diagnosis of CAEBV are of vital importance to improve its prognosis. In summary, this atypical CAEBV case could help us recognize similar cases more easily, make the right diagnosis as early as possible, and deliver proper and timely treatment.

Keywords: Chronic active Epstein-Barr virus infection (CAEBV), Coronary artery aneurysm (CAA), Coronary artery ectasia (CAE), Lymphoproliferative disorders (LPDs), Uveitis, Hematopoietic stem cell transplantation (HSCT)

*Correspondence: liugangbch@sina.com

†Haijuan Xiao and Bing Hu contributed equally to this work

1 Department of Infectious Diseases, Beijing Children's Hospital, Capital Medical University, National Center for Children's Health, Beijing, China

Full list of author information is available at the end of the article

\section{Background}

Epstein-Barr virus (EBV) is a ubiquitous virus infecting more than $90 \%$ of the population worldwide. EBV infection in humans is usually asymptomatic and persists as a lifelong latent infection [1]. However, the infection or 
reactivation of EBV could result in various lymphoproliferative disorders (LPDs), including infectious mononucleosis (IM) and hematologic malignancies [2]. Chronic active EBV infection (CAEBV) is a severe disease with high morbidity and mortality, which exhibits a predisposition in East Asian populations. As a type of LPD, the clonal expansion of EBV-infected T or NK cells plays a central role in the disease's pathogenesis. However, the detailed pathogenesis of CAEBV and the mechanism by which EBV induces proliferation of $\mathrm{T}$ and NK cells are not known [1]. CAEBV is characterized by chronic or recurrent IM-like symptoms, such as fever, hepatosplenomegaly, lymphadenopathy, and liver dysfunction. However, CAEBV can also have other less frequent clinical presentations, or even fetal complications, such as central nervous system involvement, coronary artery aneurysm (CAA), interstitial pneumonia, digestive tract disorders, uveitis, and hemophagocytic lymphohistiocytosis (HLH) [3]. The prognosis of CAEBV is poor, and a series of therapies has been attempted, including anti-viral agents and immunosuppressors. However, hematopoietic stem cell transplantation (HSCT) has been shown to be the only potentially effective treatment [1].

Clonal proliferation of EBV-infected $\mathrm{T}$ or NK cells implies that CAEBV has a malignant nature. However, CAEBV is a chronic disease, and patients may remain in a stable condition for years without effective treatment [4]. Overt malignant lymphoma often occurs after a long course of disease. Some researchers propose that CAEBV is a continuous spectrum ranging from a smoldering phase to overt lymphoma [4]. It is commonly believed that hosts with normal immune functions possess the ability to recognize EBV-infected $\mathrm{T}$ and NK cells, and CAEBV patients are thus thought to have some defects in immunological function that cause inefficient recognition and/or killing of EBV-infected cells [1]. However, CAEBV patients have not been found to have obvious immunodeficiency until the present day [5]. Nevertheless, it should be noted that some immunocompromised patients have accompanying EBV infections, and their clinical manifestations are analogous to CAEBV [6]. The mutations of several genes, including SH2D1A, XIAP, CD27, CD70, MAGT1, and PRKCD, are shown to cause hosts to be susceptible to chronic or even fetal EBV infections [7]. Therefore, genetic testing is necessary to distinguish CAEBV from these primary immunodeficiency diseases (PIDs).

Coronary artery ectasia (CAE) is an uncommon cardiovascular disorder that is defined as localized or diffuse dilatation of the coronary lumen. CAA describes local dilatation in the coronary lumen that is 1.5 -fold greater than in normal adjacent segments [8]. CAA could be seen in various disorders, including atherosclerosis, systemic inflammatory vasculitis (e.g., Kawasaki disease, Behcet's disease), hereditary collagen defects (e.g., Marfan syndrome), infectious diseases (e.g., bacteria, mycobacteria), and congenital malformations [9]. Uveitis describes inflammation of the uvea, which contains the iris, ciliary body, and choroid. As intraocular inflammation can affect surrounding tissues, clinical uveitis may comprise inflammation of the retina, optic disc, and vitreous [10]. Uveitis may be the result of infectious (e.g., human herpes virus, tuberculosis, syphilis), non-infectious (mostly autoimmune or autoinflammatory), or masquerade (e.g., lymphoma) causes [11]. In this article, we will introduce a special CAEBV case of a patient who had no typical IM-like symptoms at the early stage, but whose illness manifested as uveitis, cataract, and cardiovascular involvement (CAA).

\section{Case presentation}

In July 2016, a 4-year-old girl was admitted to our department complaining of decreased vision and cough after physical activities. Ten months before hospitalization, she suffered from blurred vision, which grew rapidly worse within one month, until only light perception remained. In her local hospital, she was diagnosed with uveitis and cataract, and received prednisone, ciclosporin $\mathrm{A}$, and local symptomatic treatment. The ocular lesions did not further exacerbate. Three months before hospitalization, the girl began to cough after exercise, with no fevers or other symptoms. Examinations showed normal blood routines and biochemical indicators, as well as a slightly increased erythrocyte sedimentation rate (ESR, $29 \mathrm{~mm} / \mathrm{h}$ ). There were no positive findings from the pulmonary CT scan or electrocardiogram, while an ultrasonic cardiogram showed bilateral CAAs, hypertrophic interventricular septum and left ventricular wall, and mitral and aortic valve insufficiency. Other significant findings were increased EBV-DNA $\left(3.29 \times 10^{4}\right.$ copies/ $\mathrm{mL}$ ) in the peripheral blood, and positive EBV antibodies (EBV-CA-IgG, EBV-EA-IgA, and EBV-NA-IgG). She was given aspirin and ganciclovir, and the cough subsided. This patient did not suffer from recurrent infections, having no other medical history and no family history of PID. She had an elder sister (17 years old), who was healthy with no known diseases. Physical examination showed vision loss (only light perception remaining), systolic murmur at the apex, and slight hepatosplenomegaly.

The examinations after hospitalization showed generally normal brain MRI manifestations, and similar results for ophthalmic tests and the ultrasonic cardiogram as before (inner diameters of left and right coronary arteries: $5.0 \mathrm{~mm}$ and $5.7 \mathrm{~mm}$ respectively). The pulmonary CT scan showed extensive parenchymal and interstitial lesions of the lungs bilaterally (Fig. 1a), and abdominal 

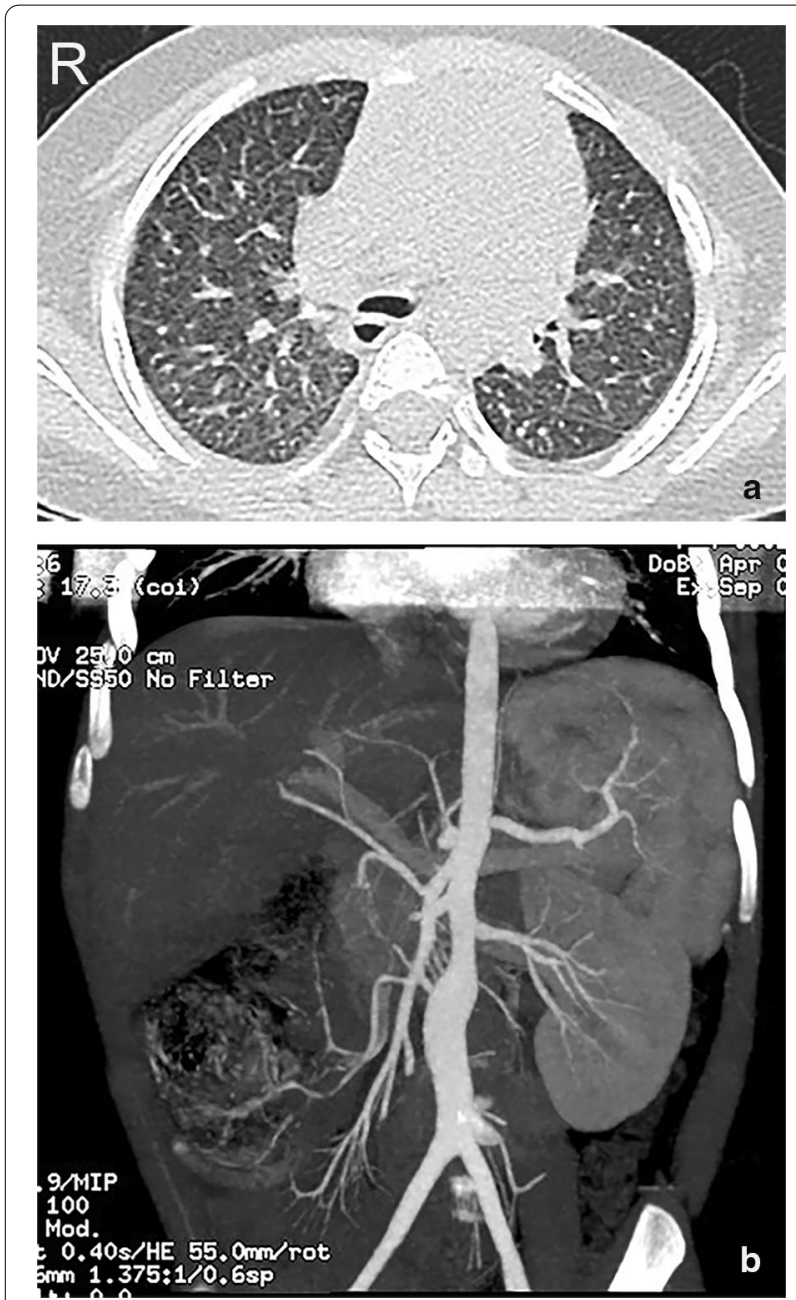

Fig. 1 Chest and abdominal CT scan findings. a Extensively parenchymal and interstitial lesions of bilateral lungs are shown. b Thickened aortic wall, and stenosis and dilation of segmental abdominal aorta are shown

CT scan revealed a thickened aortic wall, as well as stenosis and dilation of the segmental abdominal aorta (Fig. 1b). There were no apparent abnormal findings in other vessels. Blood EBV-DNA and EBV antibodies were still positive, but autoantibodies were negative. There was no evidence for other infections, including other human herpes viruses [such as herpes simplex virus (HSV), varicella zoster virus (VZV), cytomegalovirus (CMV), and human herpes virus 8 (HHV-8)], human immunodeficiency virus (HIV), tuberculosis, toxoplasmosis, and syphilis. The immunoglobulin and complement levels were within normal range. Lymphocyte subgroups showed an increased percentage of CD3 $+\mathrm{T}$ cells and a decreased percentage of B cells and NK cells. The proportion of CD4 $+\mathrm{T}$ cells increased, and the ratio of CD4 $+\mathrm{T}$ to $\mathrm{CD} 8+\mathrm{T}$ cells was also elevated (Table 1). A bone marrow smear was near normal, while bone marrow biopsy showed much infiltration of lymphoid cells, which had mildly irregular nuclei (Fig. 2a). Positive CD3/CD5/CD7/ CD2 (partially)/TIA-1/GrB (sparsely)/ki67 (80\%) and negative CD20/CD56 were revealed by immunohistochemistry, and the presence of EBV-encoded small RNAs (EBERs) was shown by in-situ hybridization (Fig. 2b). We did not find significant pathogenic genes by whole-exome sequencing (WES).

Based on her clinical manifestations, increased EBVDNA, positive EBV antibodies, and the pathological results of the bone marrow biopsy, we diagnosed the patient with CAEBV. She received allogeneic HSCT (alloHSCT) in another hospital. The EBV-DNA in the peripheral blood could not be detected after HSCT. Compared with before HSCT, the percentage of CD4+ T cells and the ratio of $\mathrm{CD} 4+\mathrm{T}$ to $\mathrm{CD} 8+\mathrm{T}$ cells both decreased after HSCT (Table 1). The cataract operation was performed after HSCT. Her CAAs did not progress, and uveitis was well controlled. The patient's vision recovered gradually over the 3 years after HSCT.

\section{Discussion and conclusions}

This is a rare CAEBV case of a patient who suffered from cardiovascular and ocular involvement. This patient showed severe and progressive CAAs and abdominal aortic lesions, which could only be blocked by HSCT. Uveitis

Table 1 Lymphocyte subsets before and 1 year after HSCT

\begin{tabular}{|c|c|c|c|}
\hline & Before HSCT & 1 year after $\mathrm{HSCT}$ & Reference values $^{a}$ \\
\hline CD3+ T lymphocytes (\%) & 91.4 & 85.7 & $55-82$ \\
\hline CD3+CD4+ T lymphocytes (\%) & 74.5 & 36.0 & $27-57$ \\
\hline CD3+CD8+ T lymphocytes (\%) & 15.4 & 41.0 & $14-33$ \\
\hline CD4/CD8 & 4.8 & $0.9^{b}$ & $1.1-2$ \\
\hline CD19+ B lymphocytes (\%) & 5.1 & 2.1 & $9-29$ \\
\hline CD16+CD56+ NK cells (\%) & 1.5 & 10.2 & $7-40$ \\
\hline
\end{tabular}

\footnotetext{
a Reference values used in Beijing Children's Hospital
}

b The value of another test at the same time was 1.25 


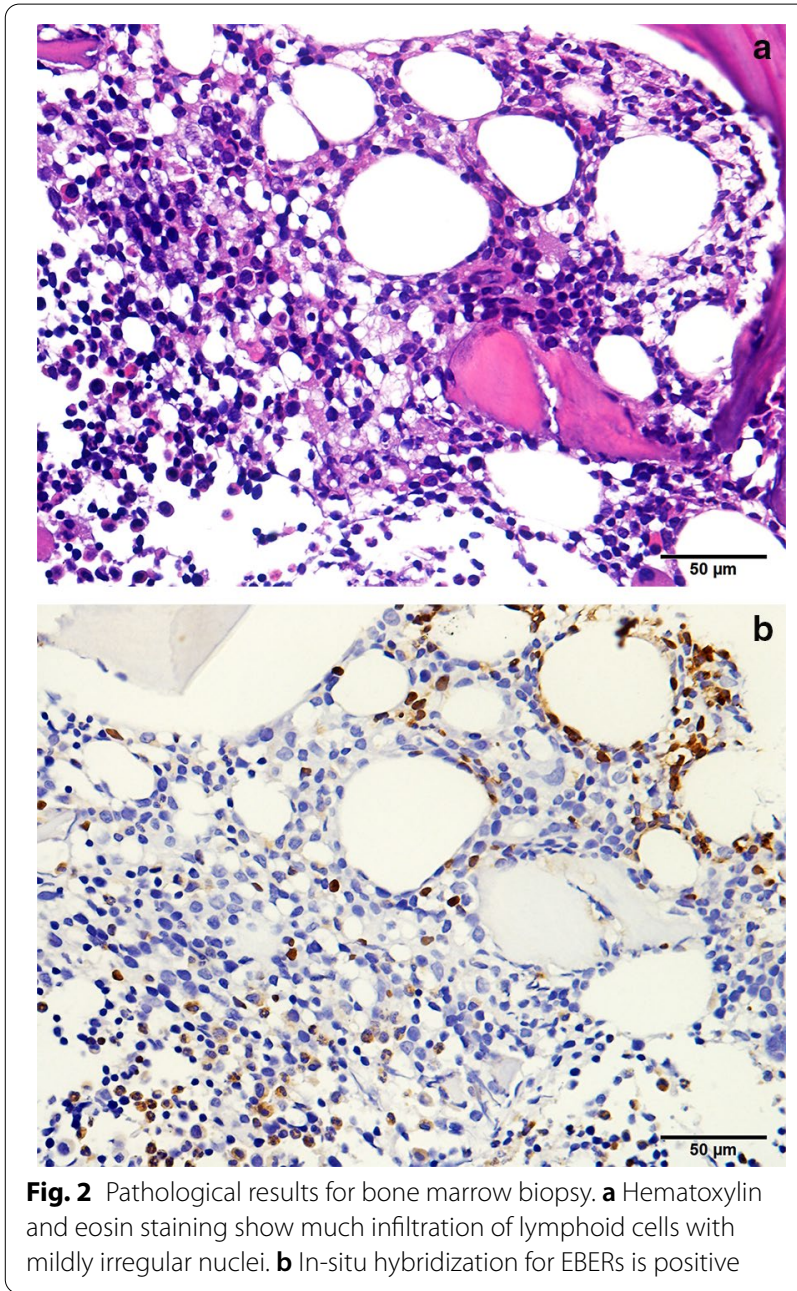

was also controlled, and vision recovered gradually after HSCT. She did not have typical IM-like symptoms at the early stage, and slight hepatosplenomegaly did not occur until the very late stage. Therefore, early recognition and diagnosis of CAEBV are of vital importance to improve the prognosis of patients like the case described.

There have been several reports about CAEBV-associated cardiovascular diseases, including CAA, aortic aneurysms, myocarditis, pericardial effusion, and others, among which CAA and myocarditis are the major complications resulting in a poor prognosis $[12,13]$. In Table 2, we summarize 20 CAEBV patients with coronary artery lesions reported in the literature, including 11 females and 9 males. There were 19 cases who had detailed descriptions about clinical features. The age at onset of CAEBV was between 2 years old and 16 years old, and 16 patients had symptoms at less than 10 years old. Eighteen patients had IM-like symptoms during the disease course. CAE, or even CAA, was found nearly simultaneously with CAEBV diagnosis in 12 cases, while these were found about 2-9 years after diagnosis in seven patients. Coronary lesions were described in detail in 13 patients: there were eight cases with bilateral $\mathrm{CAE}$, four cases with left $\mathrm{CAE}$, and one with right $\mathrm{CAE}$ only. The most severe coronary diameter was $8.2 \mathrm{~mm}$. Only seven cases suffered from concomitant vascular lesions in the major branches of aorta. Three patients with pericardial effusion and two patients with pulmonary arterial hypertension (PAH) were noted, but no myocarditis was reported. Other organ lesions included pneumonia, nephritis, gastrointestinal diseases, and skin lesions. EBV-infected cell types were revealed in 12 cases: including 10 patients with infected $\mathrm{T}$ cells, one with infected NK cells, and one with infected $\gamma \delta \mathrm{T}$ cells. Seventeen patients showed evidence for EBV infections, and all of them had positive EBV-DNA or EBERs. However, it should be noted that EBV antibodies were negative in one patient. As for the therapy, HSCT were not performed in 12 cases, among which eight patients died for various reasons. Six patients experienced HSCT: two patients were alive, and three patients died.

The potential mechanism of CAA in CAEBV patients has not yet been discovered. The pathological results showed lymphoid vasculitis, and two mechanisms were considered to play a central role in the onset and progression of cardiovascular lesions in CAEBV: EBV-infected T or NK lymphocyte infiltration and injuries in the myocardium and vessel walls, and EBV-induced high levels of pro- and anti-inflammatory cytokines resulting in inflammatory responses $[12,14,15]$. As for the pathogenesis of CAE or CAA, the activation of matrix-degrading enzymes (especially matrix metalloproteinases [MMPs]) and enzymatic degradation of the extracellular matrix (ECM) of the media are considered to be the most critical molecular events, which ultimately lead to excessive expansive arterial remodeling $[9,16]$. This process is mediated via several factors, including increased levels of inflammatory mediators [e.g., vascular endothelial growth factor (VEGF), adhesion molecules], and induction of nitric oxide (NO) and its metabolite, which could trigger MMP formation $[9,16]$. These factors have also been shown to play an important role in the pathogenesis of CAA in Kawasaki disease (the most common cause of CAA in childhood), but their functions in CAEBV still need to be further elucidated [17-19]. It has been noted that CAA frequently occurs in association with more widespread vascular abnormalities, including aneurysms in the thoracic and abdominal aorta, as well as in the pulmonary and iliac arteries [20]. Our patient also suffered from segmental dilation of the abdominal aorta.

The reports of CAEBV-associated uveitis are rare, and the exact mechanisms are not fully understood. Infectious uveitis could arise from local infection, but is more 


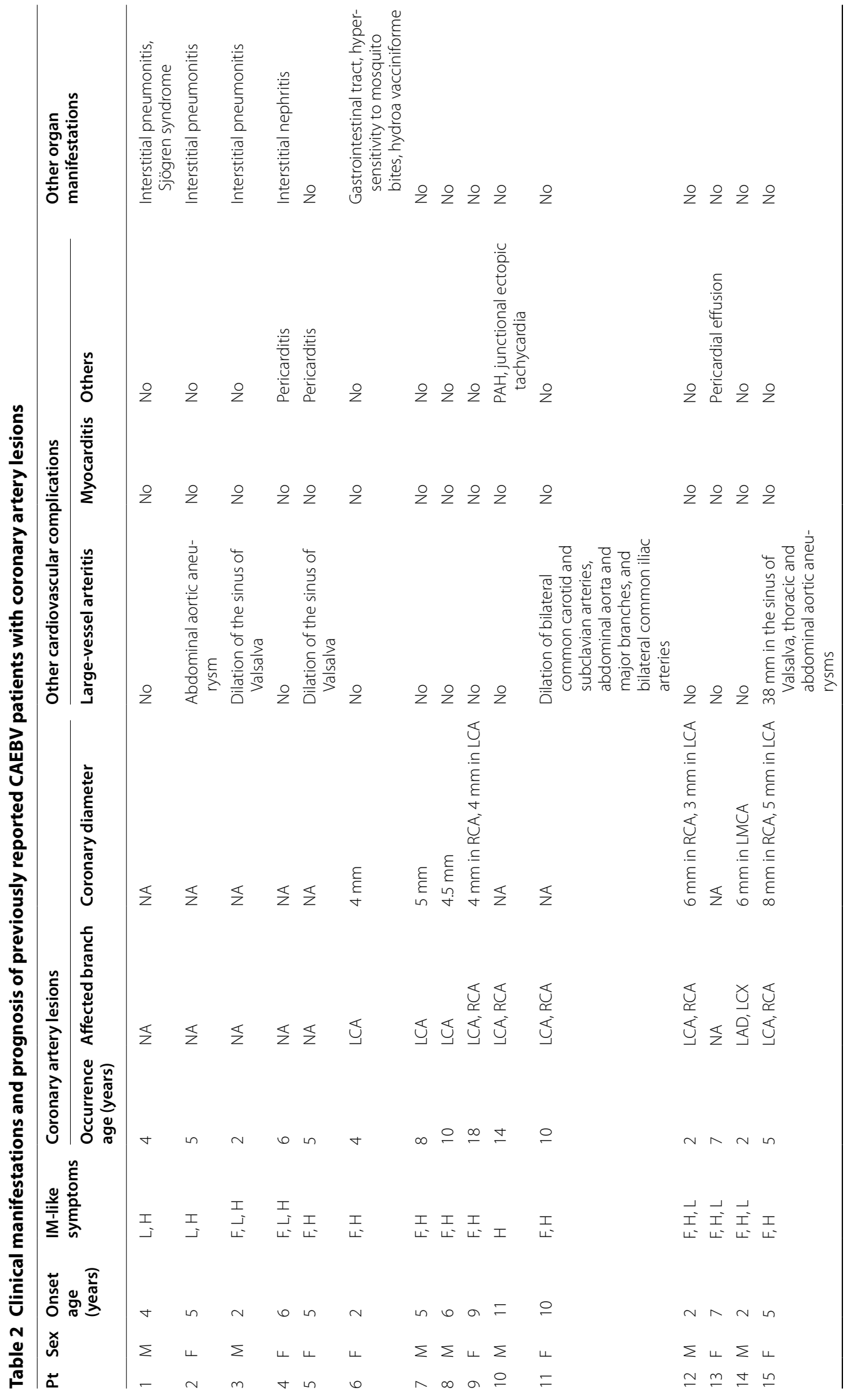




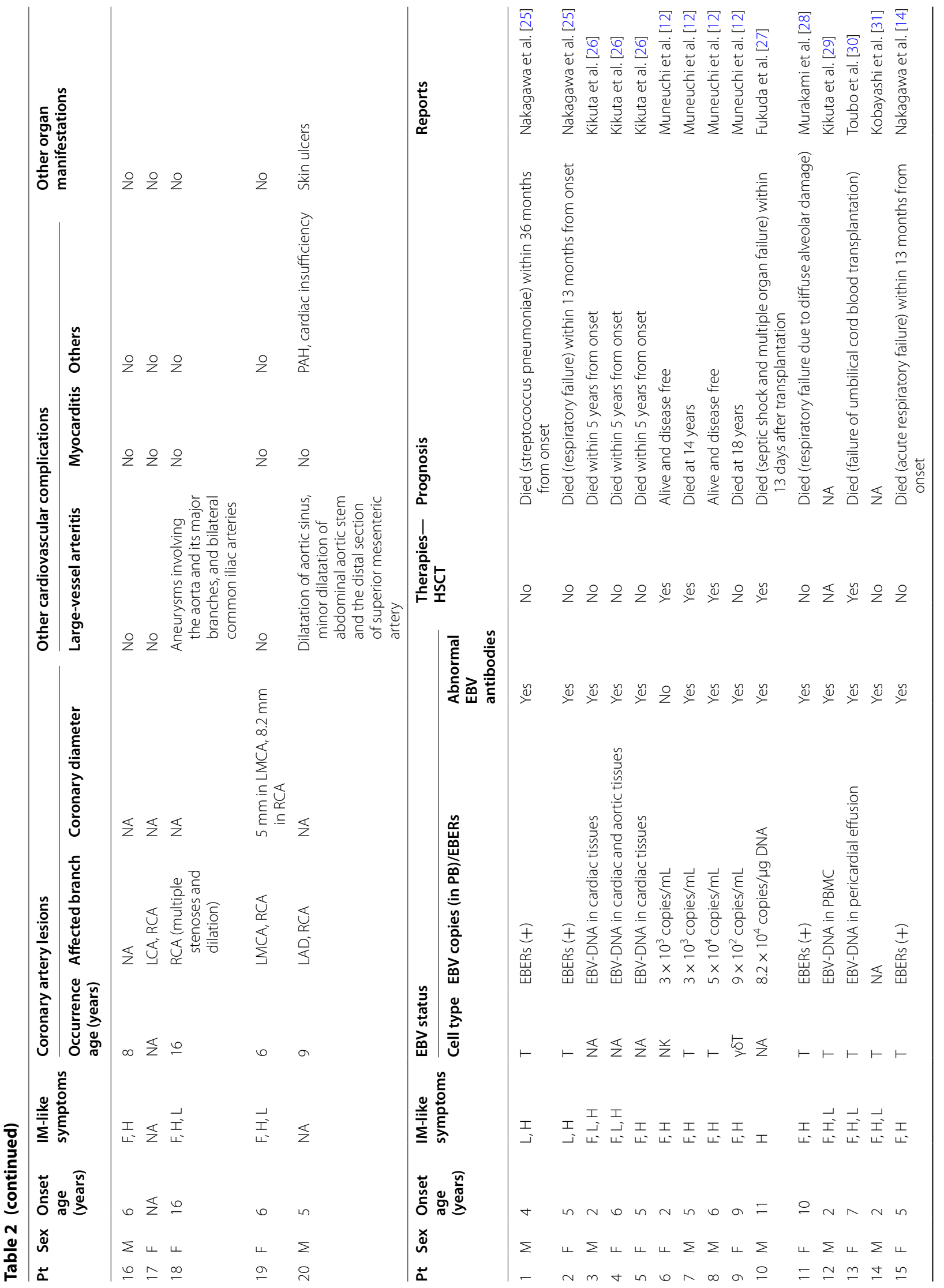




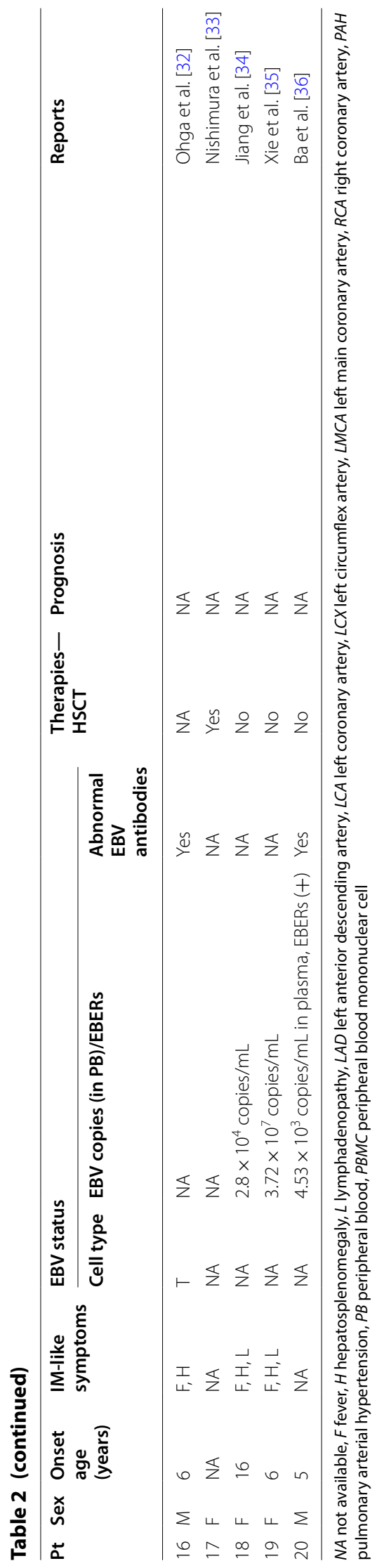


commonly due to hematogenous spread of pathogens to the uvea [10]. The pathogenic antigens are presented to the leukocytes within the eye that are activated against infectious agents, and the release of chemokines could further attract leukocytes to the inflammation sites [21]. Therefore, uveitis occurs as collateral damage from immune responses and is the result of the breach of the blood-retinal barrier that occurs due to the inflammatory cascade [10, 21]. Wong et al. [22] described three CAEBV patients whose ocular involvement ranged from anterior uveitis to a severe panuveitis with cataract, vitritis, macular edema, and optic disc swelling. The onset age of three reported patients was between 15 years old and 30 years old, and they suffered from uveitis almost simultaneously with the CAEBV diagnosis or nearly 2 years after the diagnosis. Although their ocular lesions were relieved for a while by glucocorticoid and/or acyclovir therapies, the uveitis could relapse repeatedly [22]. Morishima et al. [36] reported a 7-year-old girl with CAEBV and associated uveitis who exhibited bilateral granulomatous iridocyclitis, mild vitritis, optic disk swelling, and left facial nerve palsy nearly 2 years after the diagnosis of CAEBV. Treatment with topical steroids, systemic interleukin-2, and splenectomy relieved the symptoms [23]. There have been no reports about the direct relationship between CAEBV and cataracts. However, cataract development is common among children with uveitis and is strongly related to the extent of inflammation recurrences [24]. Therefore, we believe the cataract of our patient may be secondary to her uveitis. She received a cataract operation after the HSCT, after which her vision recovered gradually.

In summary, this atypical CAEBV case with CAA and uveitis could help us recognize similar cases more easily, make the right diagnosis as early as possible, and deliver proper and timely treatment.

\begin{abstract}
Abbreviations
allo-HSCT: Allogeneic HSCT; CAA: Coronary artery aneurysm; CAE: Coronary artery ectasia; CAEBV: Chronic active Epstein-Barr virus infection; CMV: Cytomegalovirus; EBERs: EBV-encoded small RNAs; ECM: Extracellular matrix; HHV-8: Human herpes virus 8; HIV: Human immunodeficiency virus; $\mathrm{HLH}$ : Hemophagocytic lymphohistiocytosis; HSCT: Hematopoietic stem cell transplantation; HSV: Herpes simplex virus; IM: Infectious mononucleosis; LPDs: Lymphoproliferative disorders; NO: Nitric oxide; PAH: Pulmonary arterial hypertension; PIDs: Primary immunodeficiency diseases; MMPs: Matrix metalloproteinases; VEGF: Vascular endothelial growth factor; VZV: Varicella zoster virus; WES: Whole-exome sequencing.
\end{abstract}

Acknowledgements

All the authors thank the patient and her parents for the support.

\section{Authors' contributions}

$\mathrm{HX}$ conceived the study and drafted the main manuscript. BH provided the clinical details of this case. RL provided detailed information about allo-HSCT. $\mathrm{HH}$ helped in the process of literature review. JZ, WK, RZ and LL helped in the collection of clinical details and the process of diagnosis and treatment. GL supervised the overall study. All authors read and approved the final version of the manuscript.

\section{Funding}

The study was supported by The Special Fund of the Pediatric Medical Coordinated Development Center of Beijing Hospitals Authority (No. XTZD20180501), and Beijing Hospitals Authority "Dengfeng"Talent Training Plan (DFL 20181201).

\section{Availability of data and materials}

All the data and materials used in this report are included in the manuscript.

\section{Ethics approval and consent to participate}

This study was approved by the Ethics Committee of Beijing Children's Hospital, Capital Medical University, and performed according to the Declaration of Helsinki. Written informed consents were obtained from the parents of the recipient.

\section{Consent for publication}

Written informed consents were obtained from the parents of the recipient for publication.

\section{Competing interests}

The authors declared that they had no competing interest.

\section{Author details}

${ }^{1}$ Department of Infectious Diseases, Beijing Children's Hospital, Capital Medical University, National Center for Children's Health, Beijing, China. ${ }^{2}$ Department of Hematology and Oncology, Affiliated Bayi Children's Hospital, The Seventh Medical Center of PLA General Hospital, Beijing, China. ${ }^{3}$ Department of Rheumatology, Beijing Children's Hospital, Capital Medical University, National Center for Children's Health, Beijing, China. ${ }^{4}$ Hematology Oncology Center, Beijing Children's Hospital, Capital Medical University, National Center for Children's Health, Beijing, China. ${ }^{5}$ Department of Ophthalmology, Beijing Children's Hospital, Capital Medical University, National Center for Children's Health, Beijing, China.

Received: 15 April 2020 Accepted: 1 September 2020

Published online: 29 October 2020

References

1. Fujiwara S, Kimura H, Imadome K, Arai A, Kodama E, Morio T, Shimizu N, Wakiguchi $\mathrm{H}$. Current research on chronic active Epstein-Barr virus infection in Japan. Pediatr Int. 2014;56(2):159-66.

2. Kim HJ, Ko YH, Kim JE, Lee SS, Lee H, Park G, Paik JH, Cha HJ, Choi YD, Han $\mathrm{JH}$, et al. Epstein-Barr virus-associated lymphoproliferative disorders: review and update on $2016 \mathrm{WHO}$ classification. J Pathol Transl Med. 2017:51(4):352-8.

3. Kimura $\mathrm{H}$. Pathogenesis of chronic active Epstein-Barr virus infection: is this an infectious disease, lymphoproliferative disorder, or immunodeficiency? Rev Med Virol. 2006;16(4):251-61.

4. Ohshima K, Kimura H, Yoshino T, Kim CW, Ko YH, Lee SS, Peh SC, Chan JK, Group CS. Proposed categorization of pathological states of EBV-associated T/natural killer-cell lymphoproliferative disorder (LPD) in children and young adults: overlap with chronic active EBV infection and infantile fulminant EBV T-LPD. Pathol Int. 2008;58(4):209-17.

5. Okuno Y, Murata T, Sato Y, Muramatsu H, Ito Y, Watanabe T, Okuno T, Murakami N, Yoshida K, Sawada A, et al. Defective Epstein-Barr virus in chronic active infection and haematological malignancy. Nat Microbiol. 2019;4(3):404-13.

6. Cohen Jl. Primary immunodeficiencies associated with EBV disease. Curr Top Microbiol Immunol. 2015;390(Pt 1):241-65.

7. Tangye SG, Al-Herz W, Bousfiha A, Chatila T, Cunningham-Rundles C, Etzioni A, Franco JL, Holland SM, Klein C, Morio T, et al. Human inborn errors of immunity: 2019 update on the classification from the International Union of Immunological Societies Expert Committee. J Clin Immunol. 2020;40(1):24-64. 
8. Markis JE, Joffe CD, Cohn PF, Feen DJ, Herman MV, Gorlin R. Clinical significance of coronary arterial ectasia. Am J Cardiol. 1976;37(2):217-22.

9. Abou Sherif S, Ozden Tok O, Taskoylu O, Goktekin O, Kilic ID. Coronary artery aneurysms: a review of the epidemiology, pathophysiology, diagnosis, and treatment. Front Cardiovasc Med. 2017:4:24.

10. Krishna U, Ajanaku D, Denniston AK, Gkika T. Uveitis: a sightthreatening disease which can impact all systems. Postgrad Med J. 2017;93(1106):766-73.

11. Deschenes J, Murray PI, Rao NA, Nussenblatt RB, International Uveitis Study Group. International Uveitis Study Group (IUSG): clinical classification of uveitis. Ocul Immunol Inflamm. 2008;16(1):1-2.

12. Muneuchi J, Ohga S, Ishimura M, Ikeda K, Yamaguchi K, Nomura A, Takada $\mathrm{H}$, Abe Y, Hara T. Cardiovascular complications associated with chronic active Epstein-Barr virus infection. Pediatr Cardiol. 2009;30(3):274-81.

13. Kimura H, Morishima T, Kanegane H, Ohga S, Hoshino Y, Maeda A, Imai S, Okano M, Morio T, Yokota S, et al. Prognostic factors for chronic active Epstein-Barr virus infection. J Infect Dis. 2003;187(4):527-33.

14. Nakagawa A, Ito M, Iwaki T, Yatabe Y, Asai J, Hayashi K. Chronic active Epstein-Barr virus infection with giant coronary aneurysms. Am J Clin Pathol. 1996;105(6):733-6.

15. Fujiwara M, Shimozono H, Ono H, Fujita N, Nishimura S, Ueda K, Kaneko M. Polyclonal proliferation of lymphocytes containing the Epstein-Barr virus genome in a patient dying of myocarditis in chronic active EpsteinBarr virus infection. J Pediatr Hematol Oncol. 2003;25(1):85-8.

16. Antoniadis AP, Chatzizisis YS, Giannoglou GD. Pathogenetic mechanisms of coronary ectasia. Int J Cardiol. 2008;130(3):335-43.

17. Senzaki H, Masutani S, Kobayashi J, Kobayashi T, Nakano H, Nagasaka H, Sasaki N, Asano H, Kyo S, Yokote Y. Circulating matrix metalloproteinases and their inhibitors in patients with Kawasaki disease. Circulation. 2001;104(8):860-3.

18. Ohno T, Igarashi H, Inoue K, Akazawa K, Joho K, Hara T. Serum vascular endothelial growth factor: a new predictive indicator for the occurrence of coronary artery lesions in Kawasaki disease. Eur J Pediatr. 2000;159(6):424-9.

19. Adewuya O, Irie Y, Bian K, Onigu-Otite E, Murad F. Mechanism of vasculitis and aneurysms in Kawasaki disease: role of nitric oxide. Nitric Oxide. 2003;8(1):15-25.

20. Manginas A, Cokkinos DV. Coronary artery ectasias: imaging, functional assessment and clinical implications. Eur Heart J. 2006;27(9):1026-31.

21. Barry RJ, Nguyen QD, Lee RW, Murray PI, Denniston AK. Pharmacotherapy for uveitis: current management and emerging therapy. Clin Ophthalmol. 2014;8:1891-911.

22. Wong KW, D'Amico DJ, Hedges TR 3rd, Soong HK, Schooley RT, Kenyon KR. Ocular involvement associated with chronic Epstein-Barr virus disease. Arch Ophthalmol. 1987;105(6):788-92.

23. Morishima N, Miyakawa S, Akazawa Y, Takagi S. A Case of uveitis associated with chronic active Epstein-Barr virus infection. Ophthalmologica. 1996;210(3):186-8.

24. Blum-Hareuveni T, Seguin-Greenstein S, Kramer M, Hareuveni G, Sharon Y, Friling R, Sharief L, Lightman S, Tomkins-Netzer O. Risk factors for the development of cataract in children with uveitis. Am J Ophthalmol. 2017;177:139-43.

25. Nakagawa A, Ito M, Saga S. Fatal cytotoxic T-cell proliferation in chronic active Epstein-Barr virus infection in childhood. Am J Clin Pathol. 2002;117(2):283-90.

26. Kikuta H, Sakiyama Y, Matsumoto S, Hamada I, Yazaki M, Iwaki T, Nakano M. Detection of Epstein-Barr virus DNA in cardiac and aortic tissues from chronic, active Epstein-Barr virus infection associated with Kawasaki disease-like coronary artery aneurysms. J Pediatr. 1993;123(1):90-2.

27. Fukuda Y, Momoi N, Akaihata M, Nagasawa K, Mitomo M, Aoyagi Y, Endoh K, Hosoya M. Pulmonary arterial hypertension associated with chronic active Epstein-Barr virus infection. Pediatr Int. 2015;57(4):731-4.

28. Murakami K, Ohsawa M, Hu SX, Kanno H, Aozasa K, Nose M. Large-vessel arteritis associated with chronic active Epstein-Barr virus infection. Arthritis Rheum. 1998;41(2):369-73.

29. Kikuta H, Taguchi Y, Tomizawa K, Kojima K, Kawamura N, Ishizaka A, Sakiyama Y, Matsumoto S, Imai S, Kinoshita T, et al. Epstein-Barr virus genome-positive T lymphocytes in a boy with chronic active EBV infection associated with Kawasaki-like disease. Nature. 1988;333(6172):455-7.

30. Toubo T, Ohga S, Takada H, Suga N, Nomura A, Ohno T, Hara T. Rheumatic fever-mimicking carditis as a first presentation of chronic active EpsteinBarr virus infection. Acta Paediatr. 2006;95(5):614-8.

31. Kobayashi I, Hamada I, Tomizawa K, Kikuta H, Sakiyama Y, Matsumoto S. Chronic Epstein-Barr virus infections associated with coronary aneurysms. Acta Paediatr Jpn. 1989;31(4):509-12.

32. Ohga S, Kimura N, Takada H, Nagano M, Ohshima K, Nomura A, Muraoka $\mathrm{K}$, Take H, Yamamori S, Hara T. Restricted diversification of T-cells in chronic active Epstein-Barr virus infection: potential inclination to T-lymphoproliferative disease. Am J Hematol. 1999;61 (1):26-33.

33. Nishimura S, Ehara S, Hanatani A, Yoshiyama M. Chronic active EpsteinBarr virus infection complicated with multiple artery aneurysms. Eur Heart J Cardiovasc Imaging. 2014;15(11):1255.

34. Jiang $S$, Li X, Cao J, Wu D, Kong L, Lin L, Jin Z, An J, Wang Y. Early diagnosis and follow-up of chronic active Epstein-Barr-virus-associated cardiovascular complications with cardiovascular magnetic resonance imaging: A case report. Medicine (Baltimore). 2016;95(31):e4384.

35. Xie XF, Huang P, Zhang L. A case of chronic active Epstein-Barr virus infection with concomitant giant coronary artery aneurysm. Zhonghua Er Ke Za Zhi. 2016;54(10):779-80.

36. Ba H, Xu L, Peng H, Lin Y, Li X, Wang H, Qin Y. Chronic active Epstein-Barr virus infection with systemic vasculitis and pulmonary arterial hypertension in a child. Front Pediatr. 2019;7:219.

\section{Publisher's Note}

Springer Nature remains neutral with regard to jurisdictional claims in published maps and institutional affiliations.

Ready to submit your research? Choose BMC and benefit from:

- fast, convenient online submission

- thorough peer review by experienced researchers in your field

- rapid publication on acceptance

- support for research data, including large and complex data types

- gold Open Access which fosters wider collaboration and increased citations

- maximum visibility for your research: over $100 \mathrm{M}$ website views per year

At BMC, research is always in progress.

Learn more biomedcentral.com/submissions 